\title{
Microdose lithium reduces cellular senescence in human astrocytes - a potential pharmacotherapy for COVID-19?
}

\author{
Tania Viel ${ }^{1}$, Shankar Chinta ${ }^{2,3}$, Anand Rane ${ }^{3}$, Manish Chamoli ${ }^{3}$, Hudson Buck ${ }^{4}$, Julie Andersen ${ }^{3}$ \\ ${ }^{1}$ Laboratory of Neuropharmacology of Aging, School of Arts, Sciences and Humanities, Universidade de São Paulo, \\ Sao Paulo, Brazil \\ ${ }^{2}$ Touro University California, Vallejo, CA 94592, USA \\ ${ }^{3}$ Buck Institute for Research on Aging, Novato, CA 94945, USA \\ ${ }^{4}$ Department of Physiological Sciences, Santa Casa de Sao Paulo School of Medical Sciences, Sao Paulo, Brazil
}

Correspondence to: Tania Viel; email: taniaviel@usp.br

Keywords: senolytics, lithium, COVID-19, cell senescence, chronic inflammation

Received: April 9, $2020 \quad$ Accepted: May 25, $2020 \quad$ Published: June 13, 2020

Copyright: Viel et al. This is an open-access article distributed under the terms of the Creative Commons Attribution License (CC BY 3.0), which permits unrestricted use, distribution, and reproduction in any medium, provided the original author and source are credited.

\begin{abstract}
Cell senescence is a process that causes growth arrest and the release of a senescence associated secretory phenotype (SASP), characterized by secretion of chemokines, cytokines, cell growth factors and metalloproteases, leading to a tissue condition that may precipitate cancers and neurodegenerative processes. With the recent pandemic of coronavirus, senolytic drugs are being considered as possible therapeutic tools to reduce the virulence of SARS-CoV-2. In the last few years, our research group showed that lithium carbonate at microdose levels was able to stabilize memory and change neuropathological characteristics of Alzheimer's disease (AD). In the present work, we present evidence that low-dose lithium can reduce the SASP of human iPSCs-derived astrocytes following acute treatment, suggesting that microdose lithium could protect cells from senescence and development of aging-related conditions. With the present findings, a perspective of the potential use of low-dose lithium in old patients from the "high risk group" for COVID-19 (with hypertension, diabetes and chronic obstructive pulmonary disease) is presented.
\end{abstract}

\section{INTRODUCTION}

Since the beginning of the coronaviral burst in December 2019, SARS-CoV-2 has widely spread in more than 50 countries around the world. The increased fatality of COVID-19 amongst older versus younger individuals has become more evident [1].

The aging process is characterized by increased levels of oxidative stress and chronic inflammation contributing to many age-related pathologies $[2,3]$. It has been suggested that increases in inflammation may be promoted by the release of pro-inflammatory and other factors from senescent cells as part of what is known as the senescence-associated secreted phenotypes (SASP) [4, 5], which includes increase in senescence-associated $\beta$-galactosidase (SA- $\beta$-gal) activity, increased levels of the cyclin-dependent kinase (CDK) inhibitors $\mathrm{p} 16$ and $\mathrm{p} 21$, and pro-inflammatory cytokines including IL-6, IL-8 and IL-1 $\alpha$ [6]. The SASP promotes the development of an inflammatory environment leading to tissue frailty contributing to many diseases including cancer, chronic obstructive pulmonary disease, diabetes and neurodegenerative diseases $[5,7-9]$.

In a recent research perspective, the use of senolytic drugs was suggested for the treatment and prevention of COVID-19 [10]. These drugs induce the apoptosis of senescent cells and reduce production of the SASP, reducing vulnerability to chronic diseases [11]. The authors described how many FDA-approved drugs including azithromycin, doxycycline and chloroquine have been shown to act as senolytics. 
Recently our research group and others have identified additional compounds that may also inhibit the inflammation associated with aging and neurodegenerative diseases. Lithium in microdose $[12,13]$, for example, was shown to enhance the maintenance of memory, decrease the density of senile plaques, and reduce neuronal cell loss both clinically and pre-clinically. A recent review highlighted the potential use of lithium as candidate for therapy of COVID-19 along with chloroquine or other drugs [14]. It is possible that one of the mechanisms by which microdose lithium may be eliciting its protective effects is via preventing inflammatory SASP induction.

In order to test this, human iPSCs-derived astrocytes were seeded in cell culture plates pre-coated with matrigel (Corning Matrigel Matrix, Tewksbury, MA, USA) and treated with different concentrations of $\mathrm{Li}_{2} \mathrm{CO}_{3}$ for $24 \mathrm{~h}$ and $48 \mathrm{~h}$. Concentrations up to $100 \mu \mathrm{M}$ showed no toxicity in the astrocytes as determined by the MTT assay (Figure 1A, 1B). Based on this analysis and our previous pre-clinical studies [13], three
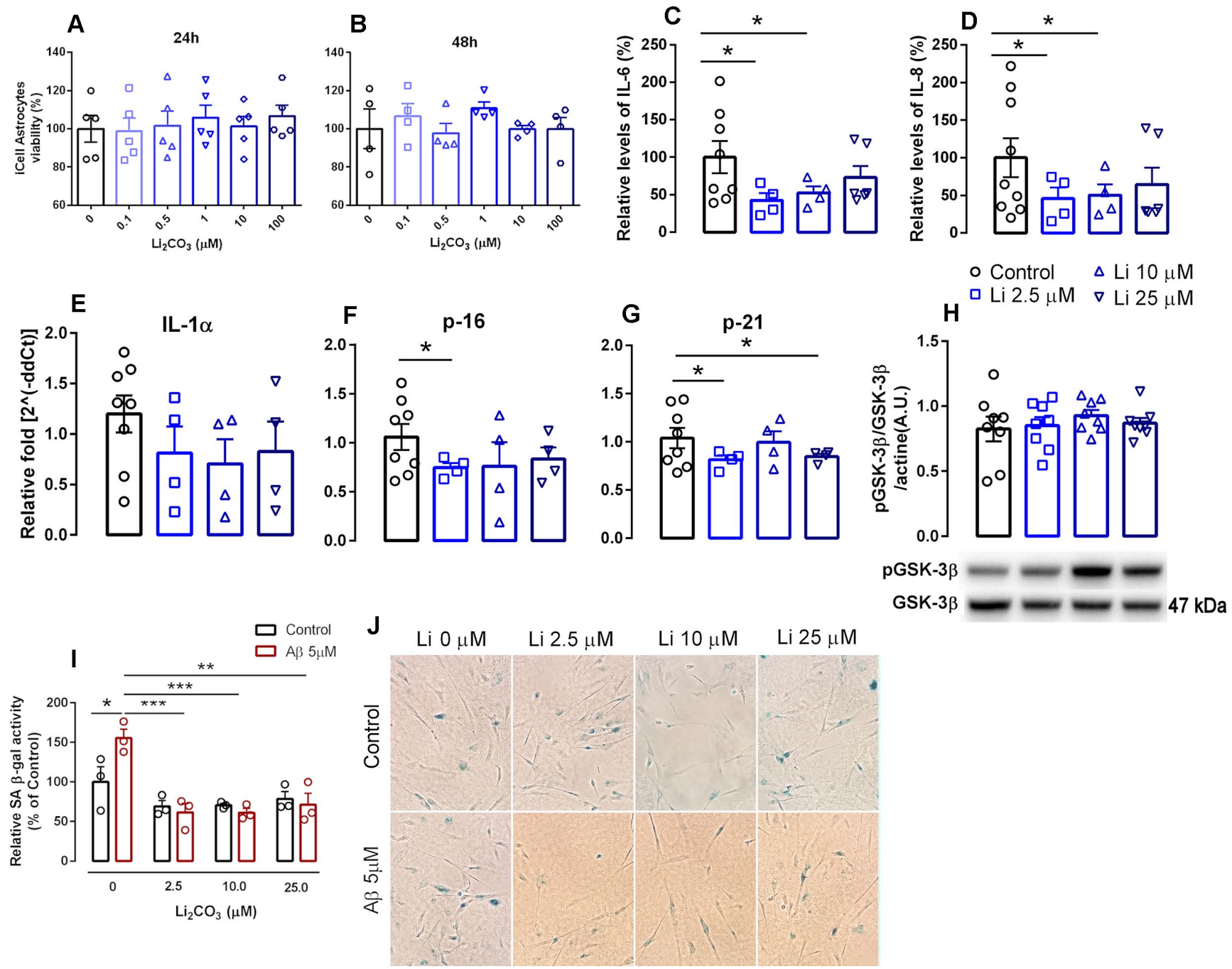

Figure 1. Effects of increasing lithium concentrations on cell viability and induction of senescence and the SASP in human iPSC-derived astrocytes. (A, B) cell viability measured by the MTT assay. Data are expressed as individual points, mean and SEM; performed in triplicate. (C, D) Relative levels of secreted IL-6 and IL-8. Conditioned media was collected $24 \mathrm{~h}$ following induction of senescence with $1 \%$ FBS and data was normalized to cell number. (E-G) RNA isolated from human iPSCs-derived astrocytes was analyzed for IL-1 $\alpha$, p16 INK4a and p21 mRNA levels by qPCR. Transcripts were normalized to actin and are shown as fold change over control levels. (H) GSK$3 \beta$ activation measured as the proportion of phosphorylated and total GSK-3 3 . Data are expressed as individual points, mean and SEM. (I) SA $\beta$-gal in iPSC-derived astrocytes in the absence and presence of $A \beta$ with increasing concentrations of lithium. Values show relative amounts of SA $\beta$-gal positive cells in three independent experiments. (J) Representative panels of SA- $\beta$ gal staining under various treatment conditions. ${ }^{*} p<0.05 ;{ }^{* *}: p<0.01 ;{ }^{* * *}: \mathrm{p}<0.001$. For $(\mathbf{C}-\mathbf{H})$, data are expressed as individual points, mean and SEM of 4-5 independent experiments. 
concentrations $(2.5 \mu \mathrm{M}, 10 \mu \mathrm{M}$ and $25 \mu \mathrm{M})$ were selected for subsequent experiments; treatments were maintained for $24 \mathrm{~h}$.

Concentrations of the hallmark SASP factors such as IL-6 and IL-8 were measured in the conditioned culture media using ELISA kits. Treatment with $2.5 \mu \mathrm{M}$ and 10 $\mu \mathrm{M} \mathrm{Li} 2 \mathrm{CO}_{3}$ promoted a $57.6 \%(\mathrm{P}<0.05)$ and $47.5 \%$ decrease $(\mathrm{P}<0.05)$, respectively, in the release of IL-6 and a $54.2 \%(\mathrm{P}<0.05)$ and $49.6 \%(\mathrm{P}<0.05)$ decrease in the release of IL-8 compared to untreated controls. Incubation of $25 \mu \mathrm{M} \mathrm{Li}_{2} \mathrm{CO}_{3}$ however did not alter the release of either cytokine (Figure 1C, 1D). These data are in agreement with recent studies from our lab and others showing anti-inflammatory properties of low-dose lithium as evidenced by reductions in pro-inflammatory cytokine density [15], Toricelli et al. (Toricelli M, Evangelista SR, Buck HS, Viel TA. Microdose lithium treatment reduced inflammatory factors and neurodegeneration in organotypic hippocampal culture of old SAMP-8 mice. Submitted to Cellular and Molecular Neurobiology, March 2020). These results are of particular interest as a very recent report shows strong association of elevated IL-6 levels with respiratory failure in COVID-19 infected patients [16].

Similar expression profiles for the senescence markers p16 and p21 and the SASP factor IL- $1 \alpha$ were also observed following treatment with $\mathrm{Li}_{2} \mathrm{CO}_{3}$ compared with untreated controls. $2.5 \mu \mathrm{M} \mathrm{Li}_{2} \mathrm{CO}_{3}$ significantly reduced expression of p16 and p21 and $25 \mu \mathrm{M} \mathrm{Li}_{2} \mathrm{CO}_{3}$ also reduced p21 expression. For IL-1 $\alpha$, however, the decrease in expression with $\mathrm{Li}_{2} \mathrm{CO}_{3}$ did not reach statistical significance (Figure 1E-1G).

Interestingly, positive effects of acute treatment with low dose lithium seems not to act via known mechanism of lithium (inhibition of GSK-3 $\beta$ activation) [17], as no differences in phosphorylation of Ser9-GSK$3 \beta$ were observed following acute treatment with low concentrations of lithium (Figure $1 \mathrm{H}$ ). In a previous study, treatment of WI-38 fibroblasts with $20 \mathrm{mM}$ lithium chloride reduced GSK3-dependent increases in p53 and p21 nuclear levels [18], indicating that microdose lithium used in the present work has different cell effects than lithium in higher concentrations.

We further confirmed the antisenescence properties of lithium using an established amyloid $\beta$-induced senescence model [19]. We observed that low dose of $\mathrm{Li}_{2} \mathrm{CO}_{3}$ including $2.5 \mu \mathrm{M}, 10 \mu \mathrm{M}$ and $25 \mu \mathrm{M}$ significantly suppressed amyloid- $\beta(\mathrm{A} \beta)$ increased SA $\beta$-gal staining in astrocytes, a hallmark of cellular senescence (Figure 1I, 1J). Overall our results highlight the potential of microdose lithium (a safe FDA approved drug) in suppressing cellular senescence.
Lithium carbonate is still widely used as a therapeutic for bipolar depression [20]. Recently, low-dose lithium has begun to be considered as a disease-modifying strategy for some neurodegenerative diseases $[13,15$, 21-24]. Its neuroprotective effects in pre-clinical models may be due to its anti-inflammatory properties $[15,25]$, Toricelli et al.

This work was originally initiated by the authors to explore the beneficial effects of low-dose lithium in brain aging and age-related neurodegenerative diseases. However, in face of the recent COVID-19 pandemic and the urgency to identify anti-viral drugs, including the potential use of FDA-approved drugs displaying senolytic properties, we believe that these findings will be important to broaden the research community therapy possibilities. The fact that microdose lithium suppresses IL-6 and recent finding correlating IL-6 level with severity of the diseases in COVID-19 patients provides a strong rationale for why lithium treatment should be tested as treatment. In this way, low-dose lithium may constitute a novel potential therapeutic to reduce the virulence of SARS-CoV-2. It is important to highlight that no side effects were verified in old people with the use of low-dose lithium $[12,26]$.

\section{MATERIALS AND METHODS}

\section{Culture of human iPSCs-derived astrocytes}

Commercially available human iPSC-derived astrocytes (iCell, \# 01434) were used for our studies. Cells were seeded at $1 \times 10^{4}$ cells $/ \mathrm{cm}^{2}$ in cell culture plates precoated with matrigel (Corning Matrigel Matrix, Tewksbury, MA, USA) and cultured to $70-80 \%$ confluence. Cells were then cultured at $37^{\circ} \mathrm{C}$ and $5 \%$ $\mathrm{CO}_{2}$ in complete DMEM media (supplemented with $\mathrm{N} 2$ supplement and $2 \%$ penicillin/streptomycin) containing $10 \%$ fetal bovine serum (FBS). Cells were grown in physiological $(3 \%)$ oxygen concentrations as previously described [27, 28]. Cells were incubated with concentrations of up to $1 \mathrm{mM} \mathrm{Li}_{2} \mathrm{CO}_{3}$ for $24-48 \mathrm{hrs}$ and toxicity verified by the MTT assay.

\section{Determination of IL-6 and IL-8 levels}

Following treatment with $2.5 \mu \mathrm{M}, 10 \mu \mathrm{M}$ and $25 \mu \mathrm{M}$ $\mathrm{Li}_{2} \mathrm{CO}_{3}$ for $24 \mathrm{~h}$, culture medium was prepared by washing cells once in PBS followed by incubation in DMEM with $1 \%$ FBS for $24 \mathrm{hr}$. The medium was collected and stored at $-80{ }^{\circ} \mathrm{C}$. Cell numbers were determined with an automated cell counter (Thermo Scientific). ELISA assays were performed using an alphaLISA IL-6 or IL-8 Immunoassay Research Kit (Perkin Elmer) following the manufacturer's 
instructions. Data was normalized to cell number and expressed as picograms per 1,000 cells.

\section{RT-qPCR analysis}

Total RNA was prepared from human astrocytes using a Direct-zol RNA MiniPrep Kit (Genesee Scientific). Integrity of RNA was verified using a nanodrop system. RT-qPCR was performed using the Universal Probe Library System (Roche, South San Francisco, CA) with the following primers and probes:

IL-1a: forward (FW) 5'-ggttgagtttaagccaatcca-3'; reverse (RV) 5'-tgctgacctaggcttgatga-3'

p16 ${ }^{\text {INK4a: }}$ FW $\quad 5^{\prime}$-cggaaggtccctcagacatc-3'; RV 5'aaactacgaaagcggggtgg- $3^{\prime}$

p21: FW 5'-ccagcatgacagatttctaccac-3'; RV 5'cttcctgtgggcggattagg- $3^{\prime}$

actin: $\quad$ 5'-ACCGAGCGCGGCTACAG-3'; 5'CTTAATGTCACGCACGATTTCC-3'

\section{Determination of GSK-3 $\beta$ activation}

For protein extractions, astrocytes were collected and homogenized in lysis buffer containing $50 \mathrm{mM}$ Tris $\mathrm{pH}$ $8.0,150 \mathrm{mM} \mathrm{NaCl}, 1 \% \mathrm{NP}-40$, a protease inhibitor cocktail (Roche) and a phosphatase inhibitor cocktail (Sigma-Aldrich). Lysates were centrifuged at $10,000 \mathrm{~g}$ for $10 \mathrm{~min}$ at $4{ }^{\circ} \mathrm{C}$ and supernatants collected. Total protein concentration was determined using the Bradford assay [29]. Proteins $(10 \mu \mathrm{g})$ were separated by $10 \%$ sodium dodecyl sulfate-polyacrylamide gel electrophoresis (SDS-PAGE) and transferred onto PVDF membranes. Membranes were blocked with TBST containing 5\% non-fat milk for 1 hour and then incubated with the primary antibody GSK-3 $\beta$ (Cell Signaling Technology, 9315, 1:1000) and phosphoGSK-3 $\beta$ (Cell Signaling Technology, 5558, 1:1000). Bands were detected using an ECL system (EMD Millipore) and quantified densitometrically. Actin (1:2000) was used as a loading control.

\section{Senescence-associated- $\beta$-galactosidase (SA- $\beta$-gal) assay}

SA- $\beta$-gal staining was performed according to the method described by Bhat and co-workers [19]. Cells were plated at $1 \times 10^{4}$ cells $/ \mathrm{cm}^{2}$ in chamber slides and treated or not with $5 \mu \mathrm{M}$ amyloid- $\beta$ for $2 \mathrm{~h}$. The medium was then replaced with fresh medium containing $0 \mu \mathrm{M}, 2.5 \mu \mathrm{M}, 10 \mu \mathrm{M}$ or $25 \mu \mathrm{M} \mathrm{Li}_{2} \mathrm{CO}_{3}$. This treatment was maintained for three days after which cells were assessed for SA- $\beta$-gal activity.
Positive (blue) cells were expressed as a percentage of total cell number.

\section{Statistical analysis}

Data were expressed as means \pm SEM and analyzed with the Graph Pad Prism program (GraphPad Software, San Diego, CA, version 6). Data were analyzed using one-way analysis of variance (ANOVA) followed by Bonferroni's test. In all analyses, only probability values $(P)$ less than 0.05 were considered statistically significant.

\section{Data availability statement}

All data generated or analyzed during this study are included in this published article.

\section{AUTHOR CONTRIBUTIONS}

TAV, SC and JKA conceived and designed the experiments; TAV and AR performed the experiments; $\mathrm{TAV}, \mathrm{SC}, \mathrm{MC}$ and $\mathrm{HSB}$ performed data acquisition and analysis; TAV, MC, HSB and JKA contributed intellectually to the paper. All authors read and approved the final manuscript.

\section{CONFLICTS OF INTEREST}

All authors declare that there are no conflicts of interest in the present work.

\section{FUNDING}

TAV received a researcher fellowship from Sao Paulo Research Foundation (FAPESP 2018/05288-6). MC is supported by the postdoctoral fellowship from Larry L. Hillblom Foundation. JKA is supported by the Pittsburgh Foundation. HSB is supported by FAPESP (2019/03486-8) and is a CNPq researcher (307252/ 2017-5).

\section{REFERENCES}

1. CDC COVID-19 Response Team. Severe outcomes among patients with coronavirus disease 2019 (COVID19) - United States, February 12-March 16, 2020. MMWR Morb Mortal Wkly Rep. 2020; 69:343-46. https://doi.org/10.15585/mmwr.mm6912e2 PMID:32214079

2. Monti D, Ostan R, Borelli V, Castellani G, Franceschi C. Inflammaging and human longevity in the omics era. Mech Ageing Dev. 2017; 165:129-38. https://doi.org/10.1016/i.mad.2016.12.008 PMID:28038993 
3. Fulop $T$, Larbi A, Dupuis $G$, Le Page A, Frost EH, Cohen AA, Witkowski JM, Franceschi C. Immunosenescence and inflamm-aging as two sides of the same coin: friends or foes? Front Immunol. 2018; 8:1960.

https://doi.org/10.3389/fimmu.2017.01960

PMID:29375577

4. Franceschi C, Campisi J. Chronic inflammation (inflammaging) and its potential contribution to ageassociated diseases. J Gerontol A Biol Sci Med Sci. 2014 (Suppl 1); 69:S4-9. https://doi.org/10.1093/gerona/glu057 PMID:24833586

5. Chinta SJ, Woods G, Rane A, Demaria M, Campisi J, Andersen JK. Cellular senescence and the aging brain. Exp Gerontol. 2015; 68:3-7. https://doi.org/10.1016/i.exger.2014.09.018 PMID:25281806

6. Sikora E, Bielak-Żmijewska A, Mosieniak G. What is and what is not cell senescence. Postepy Biochem. 2018; 64:110-118.

https://doi.org/10.18388/pb.2018 120

PMID:30656893

7. Campisi J. Aging, cellular senescence, and cancer. Annu Rev Physiol. 2013; 75:685-705.

https://doi.org/10.1146/annurev-physiol-030212183653 PMID:23140366

8. Birch J, Barnes PJ, Passos JF. Mitochondria, telomeres and cell senescence: implications for lung ageing and disease. Pharmacol Ther. 2018; 183:34-49.

https://doi.org/10.1016/i.pharmthera.2017.10.005

PMID:28987319

9. Burton DG, Faragher RG. Obesity and type-2 diabetes as inducers of premature cellular senescence and ageing. Biogerontology. 2018; 19:447-59.

https://doi.org/10.1007/s10522-018-9763-7 PMID:30054761

10. Sargiacomo C, Sotgia F, Lisanti MP. COVID-19 and chronological aging: senolytics and other anti-aging drugs for the treatment or prevention of corona virus infection? Aging (Albany NY). 2020; 12:6511-17.

https://doi.org/10.18632/aging.103001

PMID:32229706

11. Kirkland JL, Tchkonia T, Zhu Y, Niedernhofer L, Robbins PD. The clinical potential of senolytic drugs. J Am Geriatr Soc. 2017; 65:2297-301.

https://doi.org/10.1111/igs.14969

PMID:28869295

12. Nunes MA, Viel TA, Buck HS. Microdose lithium treatment stabilized cognitive impairment in patients with alzheimer's disease. Curr Alzheimer Res. 2013; 10:104-07. https://doi.org/10.2174/1567205011310010014
PMID:22746245

13. Nunes MA, Schöwe NM, Monteiro-Silva KC, BaraldiTornisielo T, Souza SI, Balthazar J, Albuquerque MS, Caetano AL, Viel TA, Buck HS. Chronic Microdose Lithium Treatment Prevented Memory Loss and Neurohistopathological Changes in a Transgenic Mouse Model of Alzheimer's Disease. PLoS One. 2015; 10:e0142267.

https://doi.org/10.1371/journal.pone.0142267 PMID:26605788

14. Nowak JK, Walkowiak J. Lithium and coronaviral infections. A scoping review. [version 2; peer review: 1 approved with reservations, 1 not approved]. F1000 Research 2020; 9:19. https://doi.org/10.12688/f1000research.22299.2

15. Wilson EN, Do Carmo S, Welikovitch LA, Hall H, Aguilar $L F$, Foret MK, lulita MF, Jia DT, Marks AR, Allard $S$, Emmerson JT, Ducatenzeiler A, Cuello AC. NP03, a microdose lithium formulation, blunts early amyloid post-plaque neuropathology in McGill-R-Thy1-APP alzheimer-like transgenic rats. J Alzheimers Dis. 2020; 73:723-39.

https://doi.org/10.3233/JAD-190862 PMID:31868669

16. Herold $T$, Jurinovic V, Arnreich $C$, Hellmuth JC, von Bergwelt-Baildon M, Klein M, Weinberger T. Level of IL6 predicts respiratory failure in hospitalized symptomatic COVID-19 patients. medRxiv. 2020. https://doi.org/10.1101/2020.04.01.20047381

17. Castillo-Quan JI, Li L, Kinghorn KJ, Ivanov DK, Tain LS, Slack C, Kerr F, Nespital T, Thornton J, Hardy J, Bjedov I, Partridge L. Lithium promotes longevity through GSK3/NRF2-dependent hormesis. Cell Rep. 2016; 15:638-50.

https://doi.org/10.1016/i.celrep.2016.03.041 PMID:27068460

18. Zmijewski JW, Jope RS. Nuclear accumulation of glycogen synthase kinase-3 during replicative senescence of human fibroblasts. Aging Cell. 2004; 3:309-17.

https://doi.org/10.1111/i.1474-9728.2004.00117.x PMID:15379854

19. Bhat R, Crowe EP, Bitto A, Moh M, Katsetos CD, Garcia FU, Johnson FB, Trojanowski JQ, Sell C, Torres C. Astrocyte senescence as a component of alzheimer's disease. PLoS One. 2012; 7:e45069.

https://doi.org/10.1371/journal.pone.0045069 PMID:22984612

20. Vieta E, Berk M, Schulze TG, Carvalho AF, Suppes T, Calabrese JR, Gao K, Miskowiak KW, Grande I. Bipolar disorders. Nat Rev Dis Primers. 2018; 4:18008. https://doi.org/10.1038/nrdp.2018.8 
PMID:29516993

21. Relaño-Ginés $A$, Lehmann $S$, Brillaud $E$, Belondrade $M$, Casanova D, Hamela C, Vincent C, Poupeau S, Sarniguet J, Alvarez T, Arnaud JD, Maurel JC, Crozet C. Lithium as a disease-modifying agent for prion diseases. Transl Psychiatry. 2018; 8:163. https://doi.org/10.1038/s41398-018-0209-4 PMID:30135493

22. Moors TE, Hoozemans JJ, Ingrassia A, Beccari T, Parnetti L, Chartier-Harlin MC, van de Berg WD. Therapeutic potential of autophagy-enhancing agents in parkinson's disease. Mol Neurodegener. 2017; 12:11.

https://doi.org/10.1186/s13024-017-0154-3

PMID:28122627

23. Limanaqi F, Biagioni F, Ryskalin L, Busceti CL, Fornai F. Molecular mechanisms linking ALS/FTD and psychiatric disorders, the potential effects of lithium. Front Cell Neurosci. 2019; 13:450.

https://doi.org/10.3389/fncel.2019.00450

PMID:31680867

24. Guttuso T Jr, Andrzejewski KL, Lichter DG, Andersen JK. Targeting kinases in parkinson's disease: a mechanism shared by LRRK2, neurotrophins, exenatide, urate, nilotinib and lithium. J Neurol Sci. 2019; 402:121-30. https://doi.org/10.1016/i.jns.2019.05.016 PMID:31129265

25. Habib A, Sawmiller D, Li S, Xiang Y, Rongo D, Tian J, Hou $H$, Zeng J, Smith A, Fan S, Giunta B, Mori T, Currier G, et al. LISPRO mitigates $\beta$-amyloid and associated pathologies in Alzheimer's mice. Cell Death Dis. 2017; 8:e2880. https://doi.org/10.1038/cddis.2017.279

PMID:28617434

26. Forlenza OV, Radanovic M, Talib LL, Gattaz WF. Clinical and biological effects of long-term lithium treatment in older adults with amnestic mild cognitive impairment: randomised clinical trial. Br J Psychiatry. 2019; 1. https://doi.org/10.1192/bjp.2019.76 PMID:30947755

27. Chinta SJ, Woods G, Demaria M, Rane A, Zou Y, McQuade A, Rajagopalan S, Limbad C, Madden DT, Campisi J, Andersen JK. Cellular senescence is induced by the environmental neurotoxin paraquat and contributes to neuropathology linked to parkinson's disease. Cell Rep. 2018; 22:930-40. https://doi.org/10.1016/i.celrep.2017.12.092 PMID:29386135

28. Woods G, Andersen JK. Screening method for identifying toxicants capable of inducing astrocyte senescence. Toxicol Sci. 2018; 166:16-24. https://doi.org/10.1093/toxsci/kfy181 PMID:30010981

29. Bradford MM. A rapid and sensitive method for the quantitation of microgram quantities of protein utilizing the principle of protein-dye binding. Anal Biochem. 1976; 72:248-54. https://doi.org/10.1006/abio.1976.9999 PMID:942051 